\title{
The Game of Negotiations: Ordering Issues and Implementing Agreements *
}

\author{
Lutz-Alexander Busch $^{\dagger} \quad$ Ignatius J. Horstmann ${ }^{\ddagger}$
}

July 1999

\begin{abstract}
In this paper we study a two-issue bargaining situation allowing for an endogenous determination of the agenda under alternative rules for implementing agreements. We uncover the settings in which different agenda structures will be employed in equilibrium, how the order in which issues are bargained over matters, and what impact the rules for implementing agreements have. We find that, if agreements are implemented as they are reached, "easy" issues are negotiated first and "hard" issues later; if agreements are implemented only after all issues are settled, then, if order is relevant, it is size of surplus that matters, with large issues settled first. We also show that all parties prefer the former rules of implementation to the latter.
\end{abstract}

Keywords: Bargaining, Agenda, Line-item veto.

${ }^{*}$ We thank Larry Ausubel, Dan Vincent and an anonymous referee for helpful suggestions.

${ }^{\dagger}$ Department of Economics, University of Waterloo, Waterloo ON N2L 3G1 and Department of Economics, University of Western Ontario, London ON N6A 5C2

${ }^{\ddagger}$ Department of Economics, University of Western Ontario, London ON N6A 5C2, and Institute for Policy Analysis, University of Toronto, Toronto ON 


\section{Introduction}

Most negotiated agreements require parties to bargain over many issues and involve such considerations as the bargaining agenda and rules for implementing the agreement. By contrast, the typical bargaining model considers the division of a single pie of either known (Rubinstein (1982) and (1985)) or unknown (Myerson and Satterthwaite (1983), Perry (1986)) size. ${ }^{1}$ While this abstraction of a single pie can be applied to bargaining over many issues, it is applicable only if the bargaining process is restricted to one in which offers must be made on all issues simultaneously, acceptance must be on all elements of the offer (or none) and no allocations can be made until all issues are decided. These restrictions mean that the standard model cannot address, among other things, issues of agenda setting or agreement implementation.

Interestingly, these two issues feature prominently in a very large literature on the "art" of negotiation. Within this literature, there are suggestions by some practitioners that, for instance, bargaining should begin with "easy" issues so that quick settlement of these issues can build trust and "bargaining momentum". "Hard" issues should only be negotiated once agreement has been reached on the easy ones. Others argue that starting with hard issues serves to convey a "tough bargaining stance" and that, if agreement can't be reached on the hard issues, there is no sense in dealing with the easy ones. Negotiators are warned to consider carefully if the agenda is "stacked" or "loaded" against them..$^{2}$ The size of issues also appears important, in that size imposes limits on any concessions one might wish to make. Concessions are seen as potentially useful since they can be invoked later on in the negotiations to obtain benefits (in the interest of "fairness"). At the same time, negotiators are warned that concessions may lead an opponent to conclude that one is in a weak bargaining position. ${ }^{3}$ Much is also written on the scheme for implementing agreements.

\footnotetext{
${ }^{1}$ For a survey of these models, see Rubinstein (1987). See also, Roth (1985).

${ }^{2}$ See, for example, Ramundo (1992) p.162, Lewis (1981) p. 224, 226.

${ }^{3}$ See, for example, Churchman (1995) p.8.
} 
Proponents of piecemeal implementation schemes argue that inefficiencies can result if implementation of an agreement on a large set of issues can be held-up by lack of agreement on a small set of issues. ${ }^{4}$ Opponents, by contrast, argue that the ability of a party to make new concessions on some previously agreed upon issue in exchange for agreement on a current, contentious issue speeds the agreement process and so is efficiency enhancing.

Given the volume of economic activity intermediated by negotiated agreements (on the order of several trillion dollars annually) and the importance that those who negotiate these agreements attach to agenda setting and implementation, it seems valuable to have a more systematic understanding of these issues. This paper seeks to do so by providing a model of multiple-issue bargaining in which many of the above matters can be addressed. The model allows for issues with different sizes of surplus and of differing complexities ("hard" vs. "easy") and permits the bargaining parties to offer on a subset of the outstanding issues. In this way, it can address the question of agenda setting and the order in which issues are bargained. The model also considers both a bargaining process in which agreements are implemented as reached and one in which implementation occurs only after all issues have been settled. As a result, it can be used to analyze the consequences of different implementation schemes.

Loosely speaking, analysis of the model reveals that, when agreements are implemented as reached, then complexity of the issues is crucial to agenda setting, with "easy" issues bargained first. When implementation occurs only after all issues have been settled, complexity is irrelevant and it is size of surplus only that matters to agenda setting, with large issues settled first.

Naturally, to undertake this analysis, it is necessary to take a stand on what constitutes a "hard", as opposed to "easy" issue. This paper takes the terms "hard" and "easy" in the practitioner literature to refer to the expected time required to reach an agreement: easy issues being ones for which agreement can be reached quickly

\footnotetext{
${ }^{4}$ Supporters of the line-item veto for the U.S. budget process often use this argument.
} 
while hard issues involve the possibility of extended bargaining before agreement is reached. Under this definition, and within the framework of non-cooperative bargaining models, an easy issue can be taken to be one for which the bargaining parties have complete information about all aspects of the bargaining setting and there is a unique equilibrium. The pie-splitting model of Rubinstein (1982) is an example. A hard issue can be taken to be one for which there is potential delay in reaching an agreement, either because of incomplete information about the bargaining setting (see Rubinstein (1985), Fudenberg, Levine and Tirole (1985) or the survey by Wilson (1987)) or because there are multiple equilibria (see Fernandez and Glazer (1991), Haller and Holden (1990) and Busch and Wen (1995)). In either of these cases, agreement may only occur after a sequence of offers has been made and rejected.

Here, the asymmetric information approach to modeling hard issues is adopted. It is assumed that there are two issues (pies). One issue has a surplus whose value is known to both bargaining parties, and is therefore the easy issue. Its value is normalized to one. The other issue is the hard issue, in the sense that the parties are asymmetrically informed about the surplus involved. One party is assumed to know the value of the surplus and the other only that it may be high or low. Two alternative implementation schemes are also considered. In one neither surplus is allocated until agreement is reached on both issues (termed "simultaneous implementation"); in the alternative scheme, the surplus from a given issue is allocated once agreement is reached on that issue, whether or not agreement has been reached on the other issue (termed "sequential implementation". 5 )

As regards the bargaining process itself, bargaining is modeled as an offer-counteroffer process. Unlike the typical model of this sort, however, an offer in this game can be either an allocation of the surplus from only one of the two issues or of that

\footnotetext{
${ }^{5}$ Ponsati and Wattson (1994) use the term "independent implementation" for this implementation rule in order to focus on the fact that the issues are decoupled. We believe that "sequential" better captures the sequentiality of bargaining together with the "independence" of agreements within this sequential process. The term "independent" is likely to cause confusion with a process in which issues may be discussed independently and simultaneously as in Jun (1989).
} 
from both issues. Moreover, an offer of either sort at any one stage of the bargaining process does not commit either party to always making offers of that sort. Thus, for instance, an offer involving the division of the surplus from one issue can be met by a counter-offer on both issues, only the same issue, or only the other issue. We maintain the common assumption that offers can only be accepted or rejected in their entirety. In particular, it is not possible to receive an offer on both issues and to accept the part of the offer dealing with one while making a counter-offer on the other. ${ }^{6}$

In this setting, we show that the order in which issues are bargained in equilibrium is determined by three things: the implementation rule, the type of the informed player and the initial beliefs of the uninformed player. Specifically, an issue-by-issue bargaining agenda arises when a low-valuation informed player faces an opponent who believes him to be likely a high-valuation type. In this situation, the informed agent uses issue-by-issue bargaining to signal type. Such an agenda is a successful signal both because it induces delay, which is relatively more costly for the high-valuation type, and because it allows the low-valuation type to make a concession on the initial issue which is only compensated for later by a concession on the subsequent issue by the opponent. The low-valuation type can arrange this initial concession in such a way that the combination of the concession and delay in the corresponding concession by the opponent on the remaining issue is too costly for the high-valuation type to follow. While this strategy is also costly to the low-valuation type, it yields a larger payoff than does pooling with the high-valuation type when the opponent's beliefs attach sufficient probability to his being high valuation.

When issue-by-issue bargaining arises, the implementation rule determines the order in which issues are bargained. When implementation takes place as agreements are reached, then the "easy" issue (i.e., the one with a known surplus) is negotiated first. The reason is that, with sequential implementation, the uninformed player's beliefs do not affect the bargaining equilibrium on the second issue if it is the easy

\footnotetext{
${ }^{6}$ For a perfect information model in which parts of offers may be accepted, see Weinberger (1998).
} 
(complete information) one. Thus, any information revealed in an initial bargain over the hard issue has no affect on future payoffs: signaling has no future value. Successful signaling therefore demands that the easy issue be dealt with first; then, a concession on this issue may convey information about the informed player's type (low valuation) that can change the equilibrium allocation of the following hard issue via the updating of beliefs.

By contrast, if implementation only occurs once agreement has been reached on all issues then, to the extent that order matters at all, it is the issue with the large surplus which is negotiated first. Since, under simultaneous implementation, all payoffs are delayed until agreement has been reached on both issues, the high- and low-valuation types have different delay costs even if only the easy issue remains to be settled. As a result, the uninformed player's beliefs matter throughout the bargaining. Successful signaling now requires a concession on the first issue which is large enough that, even if all of the second issue were allocated to the informed player, he would not be able to achieve the full information payoff for a low-valuation type. The first issue must be large enough that the uninformed player can obtain (essentially) all of his equilibrium payoff from that one issue, with all of the second issue going to the informed type. Hence, only size is important. ${ }^{7}$

A comparison of the two implementation schemes also reveals that, as long as signaling would occur under either scheme, sequential implementation dominates simultaneous implementation. Basically, the former scheme is preferred because the ability to consume as agreements are reached means that signaling is less costly for the low-valuation type.

While there are other papers that model multiple-issue bargaining, most consider the issue of how equilibrium payoffs to players are affected by different, exogenously imposed agenda and implementation rules. In the cooperative literature, Kalai (1977) and Ponsati and Watson (1994) consider situations in which payoffs are agenda-

\footnotetext{
${ }^{7}$ Note, too, that it is in the players' interest to commit to a procedure which does not allow the re-opening of past agreements. This justifies, in a limited way, the game we use here.
} 
independent. In the non-cooperative literature, Herrero (1989) and Fershtman (1990) consider whether and under what circumstances the order of bargaining (bargaining agenda) matters to the allocation of surplus when there are multiple issues. In each of these cases, however, the agenda is imposed exogenously. In addition, because these papers assume complete information, no insights on signaling can be gained.

Papers that endogenize the agenda include Bac and Raff (1996), Busch and Horstmann (1999a, 1999b, 1997), Inderst (1998), and Lang and Rosenthal (1998). The ones most closely related to the current paper are Bac and Raff (1996) and Busch and Horstmann (1999a). While Bac and Raff first claim a signaling function for endogenous agenda choice, Busch and Horstmann (1997) demonstrate that, in fact, their model only generates agenda offers because of the cost savings issue-byissue bargaining provides. More precisely, signaling occurs even with joint offers in their model. The first (and only) paper to demonstrate signaling via an issue-by-issue agenda is Busch and Horstmann (1999a). In contrast to the current paper, however, this paper allows only simultaneous implementation and has one-sided asymmetric information regarding the discount factor. As a result, it does not allow for comparisons between hard/easy versus large/small issues or between rules that allow for sequential rather than simultaneous implementation. In addition, Busch and Horstmann (1999a) only demonstrates the existence of an signaling equilibrium. In this paper, we demonstrate that this equilibrium is unique for a large range of beliefs.

The details of the model and the bargaining process are set out in Section 2. Section 3 provides our results on the bargaining equilibrium. Section 4 contains a discussion of these results and some concluding remarks. Proofs are collected in an Appendix.

\section{Model Description and Notation}

Consider a situation in which a buyer, $B$, and a seller, $S$, bargain over the price of two distinct, indivisible goods, $X$ and $Y$. The seller's valuation (cost) for each 
good is common knowledge and normalized to zero. The buyer values good $X$ at $\$ 1$; this valuation is common knowledge. The buyer's valuation for good $Y$ is $\$ V$, with the value of $V$ private information for the buyer. It is common knowledge that $V \in\left\{v_{l}, v_{h}\right\}$, with $v_{h}>1>v_{l}$ and $1>v_{h}-v_{l} .{ }^{8}$ The seller's prior that $V=v_{h}$ is given by $\omega_{0} \in(0,1)$; seller beliefs in period $t$ of the game are given by $\omega_{t}$. The buyer and seller are risk neutral and both prefer agreement earlier rather than later. These features are captured by the standard assumptions that utilities are time separable and linear in money, with future dollars discounted by the (common) discount factor $\delta \in(0,1)$.

Bargaining is via alternating offers, with one offer per discrete time period $t=$ $1,2,3, \ldots$ The buyer is assumed to make the first offer. ${ }^{9}$ An offer at time $t, P_{t}$, is a price to be paid for the transfer of the underlying good. As long as agreement has been reached on neither good, offers can be made either on just one of the two goods or on both goods together. An offer on $X$ alone is denoted by $P=p_{x} \in[0,1]$, an offer on $Y$ alone by $P=p_{y} \in\left[0, v_{h}\right]$, and an offer on both $X$ and $Y$ by $P=\left(p_{x}, p_{y}\right) .{ }^{10}$ Having received an offer, an agent can either accept it, denoted $A$ or reject it, $R$. An agent receiving an offer on both goods must either accept the offer in its entirety or reject it: it is not possible for an agent to accept only one of the prices in an offer of $\left(p_{x}, p_{y}\right)$. An offer of any particular type at any date $t$ imposes no restrictions on the types of offers made subsequently. In this way, the order in which issues are bargained over and agreements are reached is determined endogenously as part of the bargaining equilibrium rather than imposed exogenously as part of the game tree. The only

\footnotetext{
${ }^{8}$ The fact that $v_{h}>1>v_{l}$ means that $Y$ is not guaranteed to provide a larger surplus than $X$. This makes bargaining on $Y$ "hard" both because the surplus is uncertain per se and because it may be of greater or lesser economic importance than $X$. In this way, there is less ambiguity as to which issue is hard. The assumption that $v_{h}-v_{l}<1$ guarantees that the returns to the $v_{h}$ type from being perceived as the $v_{l}$ type are not so large that he would be willing to turn over all of the surplus from $X$ to the seller if doing so would convince the seller he is the $v_{l}$ type. In this sense, this assumption guarantees that $X$ is not a trivial issue to the buyer.

${ }^{9}$ This order has been chosen since it simplifies the presentation of the equilibria and focuses attention on the "interesting" subgame in which the buyers may attempt to signal.

${ }^{10}$ Since we consider unknown surplus size, share offers are precluded. Non-negative prices are, of course, equivalent to non-negative shares offers.
} 
exception to this rule is that, should an offer on some good be accepted, this offer becomes binding and not renegotiable: further offers on this good are precluded. ${ }^{11}$ The game ends as soon as an agreement on both goods exists.

Strategies for $B$ and $S$ are maps from histories into price offers or accept/reject decisions. To formalize the notion of a strategy, it is useful to distinguish among different types of histories. Specifically, let $H_{1}^{0}(t)$ denote the set of histories at the beginning of time period $t$ in which no offers have been accepted in the past and an offer (in period $t-1$ ) has just been rejected. $H_{2}^{0}(t)$ denotes the set of histories in period $t$ in which no offers have been accepted and an offer at $t$ has just been made. $H_{1}^{x}(t)$ denotes the set of histories in which an offer on $X$ has been accepted in the past and an offer at $t-1$ has just been rejected, while $H_{1}^{y}(t)$ is the corresponding set with an offer on $Y$ accepted in the past. $H_{2}^{x}(t)$ and $H_{2}^{y}(t)$ are the corresponding sets after an offer has been made at $t$, with a previous offer on $X(Y)$ accepted. The null history of the game is $H_{1}^{0}(0)=\emptyset$.

A pure strategy for $B$ is a function $f_{B}\left(t, H_{k}^{j}, V\right)$ (i.e., dependent on his type), with

$$
f_{B}:\left\{\begin{array}{rlrl}
H_{1}^{0}(t) \times\left\{v_{l}, v_{h}\right\} & \mapsto\left\{p_{x}, p_{y},\left(p_{x}, p_{y}\right)\right\} ; & & \text { if } t \text { odd } \\
H_{2}^{0}(t) \times\left\{v_{l}, v_{h}\right\} & \mapsto A, R\} ; & \text { if } t \text { even } \\
H_{1}^{x}(t) \times\left\{v_{l}, v_{h}\right\} & \mapsto\left\{p_{y}\right\} ; & \text { if } t \text { odd } \\
H_{2}^{x}(t) \times\left\{v_{l}, v_{h}\right\} \mapsto\{A, R\} ; & & \text { if } t \text { even } \\
H_{1}^{y}(t) \times\left\{v_{l}, v_{h}\right\} \mapsto\left\{p_{x}\right\} ; & & \text { if } t \text { odd } \\
H_{2}^{y}(t) \times\left\{v_{l}, v_{h}\right\} \mapsto\{A, R\} ; & & \text { if } t \text { even }
\end{array}\right.
$$

Similarly, a strategy for $S$ is a function $f_{S}\left(t, H_{k}^{j}, \omega_{t}\right)$ (i.e., dependent on his beliefs) with

$$
f_{s}:\left\{\begin{array}{lll}
H_{1}^{0}(t) \times[0,1] \mapsto\left\{p_{x}, p_{y},\left(p_{x}, p_{y}\right)\right\} ; & & \text { if } t \text { even } \\
H_{2}^{0}(t) \times[0,1] \mapsto\{A, R\} ; & & \text { if } t \text { odd } \\
H_{1}^{x}(t) \times[0,1] \mapsto\left\{p_{y}\right\} ; & & \text { if } t \text { even } \\
H_{2}^{x}(t) \times[0,1] \mapsto\{A, R\} ; & & \text { if } t \text { odd } \\
H_{1}^{y}(t) \times[0,1] \mapsto\left\{p_{x}\right\} ; & & \text { if } t \text { even } \\
H_{2}^{y}(t) \times[0,1] \mapsto\{A, R\} ; & & \text { if } t \text { odd }
\end{array}\right.
$$

\footnotetext{
${ }^{11}$ This assumption is implicit in our definition of the offers, $p_{x}, p_{y}$. Within collective bargaining, a re-opening of a previously settled issue by one party is deemed to be "bad-faith bargaining". Our results suggest, more generally, that it may be in both parties' interests to commit to such a rule. The full analysis of a general model with renegotiation, while interesting, is beyond the scope of this paper.
} 
Any two strategies $f_{B}, f_{S}$ lead to an outcome of the game. An outcome can either be i) an agreement on $X$ at time $t$ of $p_{x}$ and an agreement on $Y$ at time $\tau$ of $p_{y}$; ii) an agreement on $Y(X)$ at time $t$ of $p_{x}\left(p_{y}\right)$ and no agreement on $X(Y)$; iii) no agreement

on either $X$ or $Y$. Payoffs in each of outcomes i) and ii) depend on the rules by which agreements are implemented (for outcome iii payoffs for $B$ and $S$ are assumed to be zero). Two implementation rules are considered. In one, implementation is sequential, allowing for exchange as soon as agreement is reached on a particular good and regardless of whether agreement is ever reached on the other good. In the other implementation is simultaneous, so that all exchange takes place only after (and only if) agreement has been reached on all issues. Payoffs for each of these rules are given below (It is assumed in what follows that $t(\tau)=\infty$ if no agreement is reached on $X(Y))$.

\section{Definition 1 (Sequential Implementation)}

Under sequential implementation exchange of a given good takes place at the time of agreement on a price for that good. Agents' utilities from the strategy pair $\left(f_{B}, f_{S}\right)$ leading to agreements $\left(p_{x}, t\right)$ and $\left(p_{y}, \tau\right)$ are:

$$
\begin{aligned}
& U_{B}\left(f_{B}, f_{S}\right)=U_{B}\left(\left(p_{x}, t\right),\left(p_{y}, \tau\right)\right)=\delta^{t-1}\left(1-p_{x}\right)+\delta^{\tau-1}\left(V-p_{y}\right), \\
& U_{S}\left(f_{B}, f_{S}\right)=U_{S}\left(\left(p_{x}, t\right),\left(p_{y}, \tau\right)\right)=\delta^{t-1} p_{x}+\delta^{\tau-1} p_{y} .
\end{aligned}
$$

\section{Definition 2 (Simultaneous Implementation)}

Under simultaneous implementation exchange of no good takes place unless agreement has been reached on the prices of all goods. Agents' utilities from the strategy pair $\left(f_{B}, f_{S}\right)$ leading to agreements $\left(p_{x}, t\right)$ and $\left(p_{y}, \tau\right)$ are:

$$
\begin{aligned}
U_{B}\left(f_{B}, f_{S}\right) & =U_{B}\left(\left(p_{x}, t\right),\left(p_{y}, \tau\right)\right)=\delta^{\max \{t, \tau\}-1}\left(1-p_{x}+V-p_{y}\right), \\
U_{S}\left(f_{B}, f_{S}\right) & =U_{S}\left(\left(p_{x}, t\right),\left(p_{y}, \tau\right)\right)=\delta^{\max \{t, \tau\}-1}\left(p_{x}+p_{y}\right)
\end{aligned}
$$

As is well known, bargaining games of sort have a large number of Perfect Bayesian Equilibria. In what follows, we focus attention on a subset of these equilibria. This 
subset is defined by a set of belief restrictions similar to those imposed in Rubinstein (1985). While we believe these restrictions are plausible, their main function is to guarantee that the equilibria displayed subsequently are robust in the sense of not being supported either by some carefully constructed combination of "strange" offequilibrium path beliefs or by some complicated structure of punishment paths that exploit a multiplicity of equilibria. ${ }^{12}$ The restrictions are given by the following three assumptions.

\section{Assumption 1}

If $\omega_{t}=0$ then $\omega_{t+k}=0$ and if $\omega_{t}=1$ then $\omega_{t+k}=1, \forall k=1,2, \ldots$

\section{Assumption 2}

Suppose that at date $t$ and after history $H_{1}^{j}(t), j=0, x$, seller beliefs are such that $0<\omega_{t}<1$. Consider continuation strategies for the buyer and seller, $f_{B}\left(H_{1}^{j}\left(t^{\prime}\right), V, t^{\prime}\right)$, $f_{S}\left(H_{1}^{j}\left(t^{\prime}\right), \omega_{t^{\prime}}, t^{\prime}\right), t^{\prime} \geq t$, such that $f_{B}(\cdot)$ specifies an offer at date $t$ of $P_{t}(V)$. Suppose there exists a deviation to an offer $\widehat{P}_{t}(V) \neq P_{t}(V)$ for either $V$ such that, if the seller accepts the offer, there is a continuation equilibrium, $\left(\hat{f}_{B}\left(H_{1}^{j}(t) \cup \widehat{P}_{t}\right), \hat{f}_{S}\left(H_{1}^{j}(t) \cup \hat{P}_{t}\right)\right)$ with the feature that:

i) $U_{B}\left(\hat{f}_{B}, \hat{f}_{S}\right)>U_{B}\left(f_{B}, f_{S}\right)$ for $V=v_{l}\left(v_{h}\right)$

ii) $U_{B}\left(\hat{f}_{B}, \hat{f}_{S}\right) \leq U_{B}\left(f_{B}, f_{S}\right)$ for $V=v_{h}\left(v_{l}\right)$.

Then, the seller's beliefs upon observing $\hat{P}_{t}$ must be updated such that $\omega_{t+1}=0(1)$.

\section{Assumption 3}

Suppose that at date $t$ and after history $H_{1}^{j}(t), j=0, x$, seller beliefs are such that $0<\omega_{t}<1$. Consider continuation strategies for the buyer and seller, $f_{B}\left(H_{1}^{j}\left(t^{\prime}\right), V, t^{\prime}\right)$, $f_{S}\left(H_{1}^{j}\left(t^{\prime}\right), \omega_{t^{\prime}}, t^{\prime}\right), t^{\prime} \geq t$, such that $f_{B}(\cdot)$ specifies an offer at date $t$ of $P_{t}(V)$. Suppose there exists a deviation to an offer $\widehat{P}_{t}(V) \neq P_{t}(V)$ for either $V$ such that, if the seller

\footnotetext{
${ }^{12}$ As to the former, because our belief restrictions are stronger than those imposed by Cho-Kreps (1987) or Cho (1987), the equilibria we identify would also be equilibria under these weaker belief restrictions. Regarding the latter, Rubinstein (1985) can be used to show that there is a unique equilibrium to our game whenever it is an "as if" single pie setting. This uniqueness property is valuable for our subsequent uniqueness results.
} 
accepts the offer, there is a continuation equilibrium, $\left(\hat{f}_{B}\left(H_{1}^{j}(t) \cup \widehat{P}_{t}\right), \hat{f}_{S}\left(H_{1}^{j}(t) \cup \widehat{P}_{t}\right)\right)$ with the features that

i) $U_{B}\left(\hat{f}_{B}, \hat{f}_{S}\right)>U_{B}\left(f_{B}, f_{S}\right)$ for both $V$

ii) the time to final agreement is no longer for either type under $\left(\hat{f}_{B}, \hat{f}_{S}\right)$ than under $\left(f_{B}, f_{S}\right)$.

Then, the seller's belief upon observing $\hat{P}_{t}$ must be updated such that $\omega_{t+1} \geq \omega_{t}$. If, i) holds but instead

$\left.i i^{\prime}\right)$ the time to final agreement is no shorter for either type and strictly longer for at least one type under $\left(\hat{f}_{B}, \hat{f}_{S}\right)$ than under $\left(f_{B}, f_{S}\right)$.

Then the seller's belief upon observing $\hat{P}_{t}$ must be updated such that $\omega_{t+1} \leq \omega_{t}$.

The first two of these assumptions are fairly familiar by now and so require little discussion. ${ }^{13}$ The last assumption restricts the amount of optimism (or pessimism) which is allowed in the updating of beliefs. It requires that delay cannot convince the seller that he is more likely facing the impatient (high valuation) buyer nor can reduced delay convince him that he is more likely facing the low valuation buyer.

We also impose a restriction on the values of the key parameters, $\left(\delta, v_{h}, v_{l}\right)$. This restriction is one also found in Rubinstein (1985) and serves to rule out signaling via delay when bargaining is restricted to be only joint-offer bargaining. Since we want to focus on the possibility that agenda offers can introduce signaling where it otherwise does not exist, we want to maintain this assumption. ${ }^{14}$ The restriction requires that the discount factor and valuations be such that the high-valuation buyer is worse off making his full-information Rubinstein offer on both issues (and having it accepted immediately), rather than having one period of delay and accepting a counter offer at the full-information Rubinstein level for the low-valuation buyer. In other words,

\footnotetext{
${ }^{13}$ For those uncomfortable with Assumption 1, we note that this assumption and Assumption 2 could be replaced by (A2) in Admati and Perry (1987) without affecting the results. The use of the current set of assumptions simply allow us to re-produce the results from Rubinstein (1985) without further proof.

${ }^{14} \mathrm{Bac}$ and Raff (1996), for example, do not maintain this assumption and subsequently confuse signaling with cost savings under sequential implementation (see Busch and Horstmann (1997).)
} 
a high-valuation buyer (weak bargainer) is not so desperate as to be unwilling to wait one period to be mistaken for a low-valuation buyer (strong bargainer).

\section{Assumption 4}

$\delta\left(v_{h}-v_{l}\right)>\left(1-\delta^{2}\right)\left(1+v_{h}\right)$

A consequence of (A4) is that, when $V=v_{l}$, the buyer cannot expect to pay the fullinformation price simply by delaying agreement. Further, the seller cannot expect to screen via delay simply by making offers that give the different buyer types their full-information prices. ${ }^{15}$

Finally, we also assume as in Rubinstein (1985) that neither buyer nor seller makes an offer that is surely rejected. This restriction embodies the notion of "bargaining in good faith", a requirement commonly contained in labor laws governing collective bargaining. The term "equilibrium" in what follows refers to a pure strategy Perfect Bayesian Equilibrium that satisfies this restriction as well as Assumptions 1-3 in settings for which Assumption 4 is satisfied.

\section{Bargaining With an Agenda}

Before proceeding to an analysis of the equilibrium with agenda determination, it will prove useful to characterize the equilibrium for this game when all offers are restricted to be joint offers (i.e., of the form $\left(p_{x}, p_{y}\right)$ ). If no partial offers (offers of the form $\left(p_{x}\right)$ or $\left.\left(p_{y}\right)\right)$ are possible, the bargaining problem is a standard one-sided, incomplete information bargaining game in which the surplus is either $S_{h}:=\left(1+v_{h}\right)$ or $S_{l}:=\left(1+v_{l}\right)$. The equilibrium for this problem can be found in Rubinstein (1985) or Grossman and Perry (1986). We re-state the result here as:

\section{Result 1}

In the joint offers bargaining game with priors $\omega_{0}$ :

\footnotetext{
${ }^{15}$ This assumption rules out signaling equilibria without an agenda. While this is strong, it focuses attention on only those signaling equilibria which can be achieved only if agenda offers are possible.
} 
(i) (screening) If $\omega \geq \omega^{*}=S_{l} / S_{h}$, the (informed) buyer types will both make the

same offer of $p=\frac{\delta \omega}{1+\delta} S_{h}$ which the seller accepts. In subgames in which the seller offers he will offer $p=(1-\delta) S_{h}+\frac{\delta^{2} \omega}{1+\delta} S_{h}$. This offer is accepted only by the weak buyer and rejected by the strong buyer.

(ii) (no screening) If $\omega \leq \omega^{*}$, both types of buyer make an offer of $p=\frac{\delta S_{l}}{1+\delta}$, which the seller accepts. In subgames in which the seller offers he will offer $p=\frac{S_{l}}{1+\delta}$ and both buyers accept.

When both joint and partial offers are possible, the structure of the equilibrium depends on the implementation rule. We consider each case in turn, starting with sequential implementation.

\subsection{Sequential Implementation}

In order to characterize properties of the equilibria of this game, we proceed by establishing a sequence of lemmas which restrict the possible outcomes along any equilibrium path. We begin by examining buyer strategies. The first lemma demonstrates that there are no equilibria in which the buyer's strategy involves both types pooling on a sequence of partial offers beginning with an offer on $Y$.

Lemma 1 There exist no equilibria in which, at date $t=t^{\prime}$ and after history $H_{1}^{0}\left(t^{\prime}\right)$, $f_{B}\left(t^{\prime}, H_{1}^{0}\left(t^{\prime}\right), v_{h}\right)=f_{B}\left(t^{\prime}, H_{1}^{0}\left(t^{\prime}\right), v_{l}\right)=P_{t^{\prime}}$ and $f_{S}\left(t^{\prime}, H_{1}^{0}\left(t^{\prime}\right) \cup P_{t^{\prime}}, \omega t^{\prime}\right)=A$, if $P_{t^{\prime}}=p_{y}$.

Lemma 1 is important in that it implies that, if the buyer types pool in equilibrium, they must do so either with joint offers or partial offers beginning with $X$. As a result, this lemma goes a significant way toward ruling out equilibria in which the buyers bargain starting with the "hard" issue.

The reason that pooling strategies break down in this case is that, unless $p_{y}$ is very small, it pays the $v_{l}$ type to deviate to an offer on $X$ only. This offer, while profitable for the $v_{l}$ type, results in a lower payoff to the $v_{h}$ type even if posterior beliefs are set 
to 0 after this deviating offer has been accepted. The reason is that an offer only on $X$ creates delay that is more costly for the $v_{h}$ type than the $v_{l}$ type. While (A4) implies that delay alone is not enough to separate types, the offer only on $X$ also allows the $v_{l}$ type to make a price concession on this good that results, essentially, in a transfer of utility from the $X$ bargain to the $Y$ bargain (in which the $v_{l}$ type pays only the full-information price associated with $v_{l}$ ). This utility transfer creates a second delay cost that means that the $v_{h}$ type is unwilling to mimic the deviation. In the case of partial offers beginning with $Y$, such a deviation is successful even if $p_{y}<\delta v_{l} /(1+\delta)$. As such an offer would imply utility for the seller of less than $\delta\left(1+v_{l}\right) /(1+\delta)$, it can never occur in equilibrium.

While ruling out pooling on partial offers beginning with $Y$, the above also suggests both that the $v_{l}$ type buyer can reveal his valuation through a sequence of partial offers and that, if he does so, they must be offers beginning with $X$. The following lemma confirms this intuition and describes the features of such strategies.

Lemma 2 In any equilibrium in which, at date $t^{\prime}, t^{\prime}$ odd, and after history $H_{1}^{0}\left(t^{\prime}\right)$, $f_{B}\left(t^{\prime}, H_{1}^{0}\left(t^{\prime}\right), v_{h}\right) \neq f_{B}\left(t^{\prime}, H_{1}^{0}\left(t^{\prime}\right), v_{l}\right)$ and $f_{S}\left(t^{\prime}, H_{1}^{0}\left(t^{\prime}\right) \cup P_{t^{\prime}}, \omega_{t^{\prime}}\right)=A$, it must be that $f_{B}\left(t^{\prime}, H_{1}^{0}\left(t^{\prime}\right), v_{h}\right)=\left(p_{x}, p_{y}\right)=\frac{\delta\left(1+v_{h}\right)}{1+\delta}$ and $f_{B}\left(t^{\prime}, H_{1}^{0}\left(t^{\prime}\right), v_{l}\right)=p_{x}^{l}$, for some $p_{x}^{l} \in$ $\left[\frac{\delta}{1+\delta}, 1\right]$. At date $t^{\prime}+1, f_{S}\left(t^{\prime}+1, H_{1}^{x}\left(t^{\prime}+1\right), 0\right)=\frac{v_{l}}{1+\delta}$ and $f_{B}\left(t^{\prime}+1, H_{1}^{x}\left(t^{\prime}+\right.\right.$ 1) $\left.\cup \frac{v_{l}}{1+\delta}, v_{l}\right)=A$. The price $p_{x}^{l}$ is uniquely determined by the equality $\frac{1+v_{h}}{1+\delta}=$ $1-p_{x}^{l}+\delta\left(v_{h}-\frac{v_{l}}{1+\delta}\right)$.

In the lemma, the important features of the price $p_{x}^{l}$ are that: i) the seller prefers a strategy of accepting $p_{x}^{l}$ and offering $v_{l} /(1+\delta)$ on $Y$ over one of rejecting $p_{x}^{l}$ and countering with a joint offer of $\left(1+v_{l}\right) /(1+\delta) \quad\left(p_{x}^{l}>\delta /(1+\delta)\right)$; ii) the $v_{h}$ type buyer is indifferent between a joint offer of $\delta\left(1+v_{h}\right) /(1+\delta)$ and mimicking the $v_{l}$ type. In essence, the $v_{l}$ type signals here both by inducing delay and making a price concession on $X$. The combination of the two is sufficiently costly for the $v_{h}$ type that he chooses not to mimick. Because signaling is only relevant for the bargain over 


\section{$Y, Y$ bargaining occurs second.}

Lemmas 1 and 2 have two important implications. First, there can be no equilibria in which the buyer's strategy involves partial offers beginning with $Y$. In any equilibrium, either pooling or separating, the buyer's strategy involves either joint offers or partial offers beginning with $X$. Second, the buyer can use the agenda to signal type and does so by making partial offers beginning with $X$ when $V=v_{l}$. In short, the buyer never bargains on hard issues first but may choose to bargain sequentially starting with the easy issue as a means of signaling bargaining strength. The reader should also note that these results rely on only the belief restrictions given by Assumptions 1 and 2 above.

An argument analogous to that employed in Lemma 1 can be used to show next that, if the buyer's strategy involves both types pooling on a joint offer, then this outcome can only be maintained as an equilibrium for sufficiently low price offers. For higher prices the $v_{l}$ type gains by a deviation to partial offers beginning with $X$ (as in lemma 1). In particular, it must be that:

Lemma 3 If there is an equilibrium in which, at date $t=t^{\prime}$ and after history $H_{1}^{0}\left(t^{\prime}\right)$, $f_{B}\left(t^{\prime}, H_{1}^{0}\left(t^{\prime}\right), v_{h}\right)=f_{B}\left(t^{\prime}, H_{1}^{0}\left(t^{\prime}\right), v_{l}\right)=P_{t^{\prime}}$ and $f_{S}\left(t^{\prime}, H_{1}^{0}\left(t^{\prime}\right) \cup P_{t^{\prime}}, \omega_{t^{\prime}}\right)=A$, then, if $P_{t^{\prime}}=\left(p_{x}, p_{y}\right), p_{x}+p_{y} \leq \bar{p}=\frac{\delta\left(1+v_{l}\right)}{1+\delta}+(1-\delta) v_{l}$.

The price $\bar{p}$ above corresponds to the pooling price offer in the screening equilibrium of Result 1 for initial beliefs of $\omega^{P}=\omega^{*}+\left[\left(1-\delta^{2}\right) v_{l}\right] /\left(\delta\left(1+v_{h}\right)\right)$. This cutoff on beliefs is strictly less than 1 as long as $\delta\left(v_{h}-v_{l}\right)>\left(1-\delta^{2}\right) v_{l}$, which is guaranteed by (A4). An implication of the lemma is that, for beliefs $\omega_{t} \geq \omega^{P}$, strategies of the type described in Result 1 cannot be part of an equilibrium when partial offers are available. More generally, there can be no equilibria in which buyer types pool on a joint offer with price above $\bar{p}$. This restriction will prove useful in ruling out buyer pooling for large values of $\omega_{0}$.

Turning to the seller, results similar to those for the buyer can be shown to hold when the seller makes offers that both buyer types accept in equilibrium. Specifically, 
Lemma 4 If there is an equilibrium in which, at $t=t^{\prime}$ and after history $H_{1}^{0}\left(t^{\prime}\right)$, $f_{S}\left(t^{\prime}, H_{1}^{0}\left(t^{\prime}\right), \omega_{t^{\prime}}\right)=P_{t^{\prime}}$ and $f_{B}\left(t^{\prime}, H_{1}^{0}\left(t^{\prime}\right) \cup P_{t^{\prime}}, v_{l}\right)=f_{B}\left(t^{\prime}, H_{1}^{0}\left(t^{\prime}\right) \cup P_{t^{\prime}}, v_{h}\right)=A$, then, if $P_{t^{\prime}}=\left(p_{x}, p_{y}\right), p_{x}+p_{y} \leq \frac{1+v_{l}}{1+\delta}$. If $P_{t^{\prime}}=p_{y}, p_{y} \leq \frac{1+v_{l}-\delta^{2}}{1+\delta}$.

As with pooling offers by the buyer, offers by the seller that induce no information revelation must involve low prices. Otherwise, rather than accepting the offer, the $v_{l}$ type buyer can reject and counter with an offer that signals type (i.e., an offer that the $v_{l}$ type prefers but the $v_{h}$ type does not) and that the seller accepts.

Since the outcomes in Lemma 4 result in utility for the seller of $\left(1+v_{l}\right) /(1+\delta)$, such strategies will be adopted only if $\omega_{t}$ is small. In this case, joint offers yield the seller the same utility as partial offers beginning with $X$ and so the seller has no strict incentive to utilize the latter. Thus, if the seller is to use partial offers, they must either be pooling ones beginning with $X$ (the easy issue) or involve screening on the seller's part. The next lemma shows that, as long as $\omega_{t}$ is big enough, there exist no equilibria in which the seller screens using partial offers beginning with $Y$.

Lemma 5 There exists a value $\underline{v}=\frac{v_{h}^{2}}{1+2 v_{h}}$ such that, if $v_{l} \geq \underline{v}$ and there is an equilibrium in which, at $t=t^{\prime}$ and after history $H_{1}^{0}\left(t^{\prime}\right)$ such that $\omega_{t^{\prime}} \geq \omega^{P}$, $f_{S}\left(t^{\prime}, H_{1}^{0}\left(t^{\prime}\right), \omega_{t^{\prime}}\right)=P_{t^{\prime}}$ and $f_{B}\left(t^{\prime}, H_{1}^{0}\left(t^{\prime}\right) \cup P_{t^{\prime}}, v_{h}\right)=A, f_{B}\left(t^{\prime}, H_{1}^{0}\left(t^{\prime}\right) \cup P_{t^{\prime}}, v_{l}\right)=R$, then $P_{t^{\prime}}=\left(p_{x}, p_{y}\right)$.

The essence of the proof here is twofold. First, the seller has a strict disincentive for using partial offers. In particular, whatever the seller can accomplish with partial offers (in terms of screening or pooling the buyer types) he can also accomplish with joint offers yielding him strictly higher utility. Thus, the seller must use partial offers only because of some threat that the buyer can credibly implement to reject a joint offer should the seller deviate to one. Since a separating outcome benefits the seller, the only credible threat can involve some sort of buyer pooling. For large enough values of $\omega_{t}$, no such pooling type equilibria exist (as long as $v_{l}$ is not too small.) As a result, the buyer cannot credibly reject the joint offer. 
Together, these results imply that, for large enough values of $\omega_{t}$, there can be no equilibria in which either the buyer or the seller use partial offers beginning with $Y$. We show finally that there is, in fact, a unique equilibrium in this case, involving partial offers by the $v_{l}$ type buyer beginning with $X$. This equilibrium is the separating one described in Lemma 2 above.

Result 2 If $v_{l} \geq \underline{v}$ and given Assumptions 1 -4, there exists a unique equilibrium to the bargaining game with sequential implementation for all initial beliefs $\omega_{0} \geq \omega^{P}$. This equilibrium is a separating one and is defined by: $f_{B}\left(1, H_{1}^{0}(1), v_{h}\right)=P_{1}^{h}$, where $P_{1}^{h}$ is a joint offer with the feature that $p_{x}+p_{y}=$ $\frac{\delta\left(1+v_{h}\right)}{1+\delta} ; f_{B}\left(1, H_{1}^{0}(1), v_{l}\right)=P_{1}^{l}$, where $P_{1}^{l}$ is a partial offer on $X$ given by $p_{x}=$ $\delta \frac{1+\left(v_{h}-v_{l}\right)}{1+\delta}-(1-\delta) v_{h}$. For the seller, $f_{S}\left(1, H_{1}^{0}(1) \cup P_{1}^{h}, \omega_{0}\right)=f_{S}\left(1, H_{1}^{0}(1) \cup\right.$ $\left.P_{1}^{l}, \omega_{0}\right)=A$. Further, in the case of the offer $P_{1}^{l}, f_{S}\left(2, H_{1}^{0}(1) \cup P_{1}^{l}, 0\right)=\frac{v_{l}}{1+\delta}$ and $f_{B}\left(2, H_{1}^{x}(2) \cup \frac{v_{l}}{1+\delta}, v_{l}\right)=A$.

There are several points worth noting here. First, an issue-by-issue agenda is a valuable signaling device when one's opponent believes one is in a weak bargaining position ( $\omega_{0}$ large) when in fact the opposite is true $\left(V=v_{l}\right)$. Signaling is accomplished by the strong bargaining type $\left(v_{l}\right)$ making a price offer on $X$ only that is sufficiently large that, even when coupled with a subsequent low price on $Y$ of $v_{l} /(1+\delta)$, the weak bargaining type $\left(v_{h}\right)$ doesn't find the agenda profitable. Basically, the combination of a high price on $X$ and delay in consuming $Y$ means that the issue-by-issue agenda is too costly for the weak bargaining type to pursue. When $\omega_{0}$ is small, signaling is unnecessary as the seller offers a low price in any event.

Note second that for no value of $\omega_{0}$ is there an equilibrium in which the buyer adopts an issue-by-issue agenda beginning with $Y$. As a consequence, with sequential implementation, either the agenda is a simultaneous offer one or the buyer offers on the "easy" issue first and then the "hard" one. The prescription when there is sequential implementation then is for the informed type to bargain on the easy issue 
first. For large enough values of $\omega_{0}$, the uninformed always makes joint offers.

Finally, for values of $\omega_{0}$ sufficiently small, there is also a unique equilibrium involving joint offers of $\left(1+v_{l}\right) /(1+\delta)$ and $\delta\left(1+v_{l}\right) /(1+\delta)$ by the seller and buyer respectively. For intermediate values of $\omega_{0}, \omega_{0} \in\left[\omega^{S}, \omega^{P}\right)$ for instance, there are multiple equilibria. The separating equilibrium of Result 2 continues to be an equilibrium as is the screening equilibrium of Result 1 . Because of these two equilibria, it may be possible to construct a third equilibrium in which the seller screens using partial offers beginning with $Y$. This outcome would be supported by a "threat" to switch to the Result 1 equilibrium should the seller deviate to a joint screening offer. If strategies were additionally restricted to stationary Markov strategies, then no equilibrium involving partial offers by the seller would be supportable.

\subsection{Simultaneous Implementation}

In contrast to sequential implementation, simultaneous implementation requires the agents to reach agreement on every issue before an agreement on any one issue can be implemented. This alteration to the rules effects an important change in the nature of partial agreements. In particular, even if agreement on $Y$ has been achieved, the information asymmetry associated with $Y$ is still relevant for the bargain on $X$. The reason is that, because consumption of $Y$ cannot occur until agreement has been reached on $X$, the buyer's delay cost continues to depend on type even after an agreement on $Y$. In this way, bargaining with simultaneous implementation is very much similar to the single-pie bargaining of Rubinstein (1985). An important implication of this fact is that the distinction between "hard" and "easy" is no longer relevant in determining the order of issues. In essence, bargaining on either issue is "hard" given that the information asymmetry persists until agreement is achieved on both.

In spite of the many similarities with single-pie bargaining, there is an important dimension in which simultaneous-implementation bargaining is different. Specifically, 
because a partial agreement is binding, it is still possible for the low-valuation buyer to signal type by making a sufficiently large concession on the first issue. This ability to signal means that the order of issues may still matter. In particular, there is a minimum size concession that the low-valuation type must make on the first issue if the signal is to be credible. If this minimum is greater than the total surplus from one of the issues, then this issue cannot be settled first. Thus, under simultaneous implementation, the relevant distinction among issues is not hard versus easy (all issues are hard) but rather large versus small surplus. ${ }^{16}$

To proceed more formally, assume for the moment that a price, $p_{1}$, has been offered by the buyer and agreed to by the seller for one of the goods and that this price has revealed that the buyer has valuation $v_{l}$. Then the follow-up offer by the seller, call it $p_{2}^{s}$, and the reply by the buyer, $p_{2}^{b}$, must solve the following two inequalities to constitute equilibrium offers:

$$
\begin{aligned}
1+v_{l}-p_{1}-p_{2}^{s} & \geq \delta\left(1+v_{l}-p_{1}-p_{2}^{b}\right), \\
p_{1}+p_{2}^{b} & \geq \delta\left(p_{1}+p_{2}^{s}\right) .
\end{aligned}
$$

From these two inequalities, it follows that $p_{2}^{s}=\left(1+v_{l}\right) /(1+\delta)-p_{1}$, the full information price for the $v_{l}$ type less the already agreed upon price $p_{1}$. In cases where the offers are unrestricted, the outcome would be the full-information price, one period delayed. This price cannot be part of a signaling equilibrium, however, since (A4) implies that such a $p_{1}$ could not reveal the buyer. Therefore, if signaling is to occur, it must be that the initial price, $p_{1}$, is such that $p_{2}^{b}=0$ (the non-negativity constraint binds), in which case $p_{2}^{s}=\left(1+v_{l}-p_{1}\right)(1-\delta)$. This outcome occurs if $p_{1} \geq \delta\left(1+v_{l}\right) /(1+\delta)$; that is, if the price already agreed upon is at least as large as the uninformed player's full-information payoff when bargaining against $v_{l}$. For this price to be feasible, the issue bargained on initially must have surplus of at least this value. This constraint is the one that determines the minimum size of the initial

\footnotetext{
${ }^{16}$ This point is made in Busch and Horstmann (1999a) in the context of a bargaining model in which one agent's discount factor is the source of private information.
} 
issue.

In the interest of brevity, and since the basic ideas have been demonstrated in the previous section, we will not provide a similar list of lemmas for this case. ${ }^{17}$ The reader can verify that, as before, the $v_{l}$ type buyer will have an incentive to deviate to a partial offer from a joint offer, if the joint offer is sufficiently large relative to his full information price. Signaling arises for large enough values of $\omega_{t}$, with the $v_{h}$ type buyer making a joint offer that is his full information price and the $v_{l}$ type making a sequence of partial offers involving a concession on the first agreement. As previously, the seller always has an incentive to make joint offers, and any offer that is accepted by both buyer types yields a low total payment to the seller.

We have, therefore, the following result for simultaneous implementation:

Result 3 Under Assumptions 1-4 and with simultaneous implementation, there exists a unique equilibrium to the bargaining game for all initial beliefs $\omega_{0}>\omega^{P_{2}}$. This equilibrium is a separating one and is defined by:

$f_{B}\left(1, H_{1}^{0}(1), v_{h}\right)=P_{1}^{h}$, where $P_{1}^{h}$ is a joint offer with the feature that $p_{x}+p_{y}=$ $\frac{\delta\left(1+v_{h}\right)}{1+\delta} ; f_{B}\left(1, H_{1}^{0}(1), v_{l}\right)=P_{1}^{l}$, where $P_{1}^{l}$ is a partial offer given by $p_{1}=\left(1+v_{l}\right)+$ $\frac{v_{h}-v_{l}}{\delta}-\frac{1+v_{h}}{\delta^{2}(1+\delta)}$. For the seller, $f_{S}\left(1, H_{1}^{0}(1) \cup P_{1}^{h}, \omega_{0}\right)=f_{S}\left(1, H_{1}^{0}(1) \cup P_{1}^{l}, \omega_{0}\right)=A$. Further, in the case of the offer $P_{1}^{l}, f_{S}\left(2, H_{1}^{0}(1) \cup P_{1}^{l}, 0\right)=(1-\delta)\left[\frac{1+v_{h}}{\delta^{2}(1+\delta)}-\frac{v_{h}-v_{l}}{\delta}\right]$ and $f_{B}\left(2, H_{1}^{x}(2) \cup \frac{v_{l}}{1+\delta}, v_{l}\right)=A$.

Again, as with sequential implementation, signaling occurs through an initial high price offer and, under Assumption 3, only when $\omega_{0}$ is large. The important feature to note about this equilibrium is that, if both issues generate surplus greater than $p_{1}$, then the buyer is indifferent regarding the order in which issues are bargained. That is, the buyer still employs an issue-by-issue agenda when $V=v_{l}$ but is indifferent

\footnotetext{
${ }^{17}$ The essentials of the proofs for the analogues of Lemmas 2 and 3 can be found in Busch and Horstmann (1999a). The proof for the analogue of Lemma 4 is as in Rubinstein (1985). There is no analogue of Lemma 1 for this case. Rather, the possibilities associated with buyer pooling on the first issue are covered by the other lemmas.
} 
between the orders $X$ then $Y$ and $Y$ then $X$. Should $Y$ have surplus smaller than $p_{1}$, however, then the low-valuation buyer will again have a strict preference for an agenda that involves bargaining on $X$ first. In this case, however, it is not because $X$ is easy and $Y$ hard but simply because $Y$ 's surplus is too small.

Note also that, unlike the case of sequential implementation, there is no issue

of the buyers having differential preferences on the order in which issues are settled since nothing is consumed until all issues are settled. In particular, under sequential implementation the $v_{h}$ type prefers the $Y$ then $X$ agenda order to the $X$ then $Y$ agenda order preferred by the $v_{l}$ type, since $Y$ is the larger issue for the $v_{h}$ type. As a consequence, we do not have a restriction on $v_{l}$, which served the purpose of keeping the issue $Y$ of sufficient economic importance.

\section{Discussion and Concluding Remarks}

The results above verify the intuition that the choice of agenda in a multi-issue bargaining game can transmit information and also affect the efficiency of the bargain. The signaling function of the agenda choice becomes relevant when the opponent believes that one is in a weak bargaining position ( $\omega_{0}$ large) when in fact one is not $\left(V=v_{l}\right.$.) The willingness both to bargain issue-by-issue and to make a concession on the initial issue can credibly signal strength and so lead to an improved bargaining outcome. Of course, if the opponent already believes that one is in a strong bargaining position ( $\omega_{0}$ small), then there is no incentive to convince the opponent otherwise. It also would not pay to bear the costs an agenda imposes simply to further confirm the opponent's beliefs. We therefore predict the use of agendas only if a strong bargaining party is taken to be weak.

Our results also show that, if an agenda is used, the order of issues is relevant. If agreements are implemented sequentially, then "easy" issues should go first. The reason is that, because "hard" issues have been defined as those with asymmetric information, beliefs are relevant only in bargains over "hard" issues. Because agenda 
choice is used to signal bargaining strength and allocations are implemented as agreements are reached, signaling will be valuable only if the hard issues are taken up after the signal has been sent (the price concession has been made). As a result, the "easy" issues are bargained first and then the "hard" issues.

If implementation of agreements occurs only at the conclusion of bargaining, no "natural" order may be apparent. There is no efficiency reason to prefer one order over another and all issues are hard. In spite of these facts, order can matter even in this case. The reason is that a signal of bargaining strength can only be credible if the informed agent gives up sufficient surplus on the first issue as to be unable to re-coup it all later on the second issue. If the surplus from the first issue is small and that from the second large, even a concession by the informed agent of all the surplus from the first issue could be compensated for by obtaining a large enough share on the second issue. In this case, the informed agent would have made no actual concession and so no signaling can take place. These results indicate that it is the size of the surplus that determines the order of issues when implementation is simultaneous.

The ability to signal in this latter case does rely on the restriction to non- negative prices (the signaling result for the former case does not, however). If, for instance, negative prices could be agreed upon but total payments were limited to the value of the items, then signaling would require initial price agreements much larger than the value of both issues. If there were no constraint on valid price offers, then signaling could not occur at all. Since the seller prefers the signaling equilibrium to the pooling/screening equilibrium in the absence of agenda signaling, this fact might explain a restriction to non-negative price offers: it is in at least one party's interest. ${ }^{18}$

Our results indicate that, whenever uncertainty about an opponent's bargaining strength is important, issue-by-issue bargaining with a large initial concession can only indicate a strong opponent (in contrast to suggestions in the negotiation literature). Further, the issue on which this concession occurs depends on the way agreements are

\footnotetext{
${ }^{18}$ Compare the seller's payoff under result 1 for large $\omega$ to that under result $3: \delta \omega S_{h} /(1+\delta)<$ $\omega\left(\delta S_{h} /(1+\delta)\right)+(1-\omega) \delta\left((\delta(1+\delta)-1) S_{h}\right) /(1+\delta)$ if $\left.\omega<\omega+(1-\omega)(\delta(1+\delta)-1)\right)$, which is true.
} 
implemented. An easy issue will have to be first under sequential implementation, and will, in a sense, build "bargaining momentum" since the following bargain on the hard issue is transformed into an easy bargain given all information has been revealed. Under simultaneous implementation, by contrast, it is only important that the initial issue be large enough so as to allow a big enough concession. Size, of surplus only, and not considerations of hard or easy issues is, is all that is relevant.

Finally, it is also possible to compare the allocations that arise under simultaneous and sequential implementation and determine which scheme is preferred by the agents. If initial beliefs are such that the signaling equilibrium (Results 2 and 3 ) occurs under either rule, then the informed agent is indifferent between simultaneous and sequential implementation. The reason is that, if $V=v_{h}$, the informed obtains his full-information payoff regardless of the form of implementation. If $V=v_{l}$, the payoff is such that the $v_{h}$ type is just indifferent between taking his equilibrium payoff and mimicking the $v_{l}$ type. The only difference between the two agents' evaluations of any given pair of prices arises from the price for $\operatorname{good} Y$, consumption of which is delayed by one period under either implementation procedure. ${ }^{19}$

The uninformed agent, on the other hand, strictly prefers sequential implementation. This preference results from the fact that sequential implementation allows the agents to obtain the surplus from agreement on the first issue prior to reaching agreement on the second. This fact means that the uninformed must allocate less total surplus to the informed under sequential implementation to achieve the required indifference for the $v_{h}$ type. Thus, as long as either scheme results in issue-by-issue bargaining when $v=v_{l}$, the agents prefer sequential implementation to simultaneous implementation. In this sense, proponents of sequential arrangements like the line-item veto are correct in asserting efficiencies for such arrangements.

\footnotetext{
${ }^{19}$ This is easily seen from the following: The payoffs to the high valuation agent under sequential and simultaneous implementation are $1-p_{x}+\delta\left(v_{h}-p_{y}\right)$ and $\delta\left(1+v_{h}-p_{1}-p_{2}\right)$. They can be rewritten as $1-p_{x}+\delta\left(v_{l}-p_{y}\right)+\delta\left(v_{h}-v_{l}\right)$ and $\delta\left(1+v_{l}-p_{1}-p_{2}\right)+\delta\left(v_{h}-v_{l}\right)$ respectively, which are easily seen to differ from the low valuation agent's payoffs by the constant amount $\delta\left(v_{h}-v_{l}\right)$.
} 


\section{$5 \quad$ Appendix}

Proof of Lemma 1: Suppose there were an equilibrium in which both types offer on $Y$ first and this offer is accepted. After the acceptance the players are left with a full information bargain on $X$, for which the unique equilibrium is an offer by the seller of $1 /(1+\delta)$ which is accepted. It follows that the lowest possible $p_{y}$ in such an equilibrium would have to be $\delta v_{l} /(1+\delta)$ since otherwise the uninformed could reject and offer the low full information price on both issues next period, which will be accepted by both informed.

Now consider a deviation by the $v_{l}$ type using a sequence of partial offers starting with $X$. Under (A2) the uninformed will update beliefs to $\omega_{t+k}=0$ if he receives a partial offer $p_{x}$ and if the $v_{h}$ type strictly prefers the original strategy to the continuation path under the deviation, while the $v_{l}$ type prefers the deviation. If this partial offer is accepted, the highest possible continuation payoff to the informed if the partial offer is accepted arises if the uninformed makes the low valuation full information offer $v_{l} /(1+\delta)$. Thus, if there exists a $p_{x} \in[0,1]$ that is accepted by the seller and is such that

$$
\begin{aligned}
& v_{h}-p_{y}+\frac{\delta^{2}}{1+\delta} \geq 1-p_{x}+\delta\left(v_{h}-\frac{v_{l}}{1+\delta}\right) \\
& \text { and } \quad v_{l}-p_{y}+\frac{\delta^{2}}{1+\delta}<1-p_{x}+\delta\left(v_{l}-\frac{v_{l}}{1+\delta}\right)
\end{aligned}
$$

beliefs will be updated to $\omega_{t+1}=0$ by (A2) and stay at zero by (A1) for all continuation paths. (1) guarantees that the $v_{h}$ type finds the deviation to $p_{x}$ unprofitable while (2) guarantees that the $v_{l}$ type finds such a deviation profitable. For the seller to be willing to accept the offer $p_{x}$, it must be that acceptance yields higher utility than if the seller were to reject and counter with the price $\left(1+v_{l}\right) /(1+\delta)$ (he now is convinced of facing the low type, after all.) Such will be the case as long as $p_{x} \geq \delta /(1+\delta)$. The smallest $p_{y}$ such that the $v_{l}$ type finds this deviation profitable is given by the $p_{y}$ for which (2) holds as an equality when $p_{x}=\delta /(1+\delta)$. This value of 
$p_{y}$ is given by $p_{y}=\delta v_{l} /(1+\delta)+(1-\delta)\left(v_{l}-1\right)$. Note that this is less than the lowest a priori possible pooling $p_{y}$ offer since $v_{l}<1$.

On the other hand, since $p_{x}<1$, the largest possible value of $p_{y}$ for which the deviation is possible is given if (1) holds as an equality when $p_{x}=1$. This yields $p_{y} \leq v_{h} /(1+\delta)-\delta\left(\delta\left(v_{h}-1\right)+v_{l}\right) /(1+\delta)$ which is clearly less than the a priori largest pooling offer on $Y$. Thus the deviation is always possible.

qed

Proof of Lemma 2: Assume the buyers do separate, but that the $v_{h}$ type buyer makes an offer other than his full information offer on both pies. Then the seller will have $\omega_{t^{\prime}+1}=1$ after observing this offer and therefore will accept only joint offers $p \geq \delta\left(1+v_{h}\right) /(1+\delta)$, or partial offers $p_{x} \geq \delta /(1+\delta)$ and $p_{y} \geq \delta v_{h} /(1+\delta)$. Since for these values

$$
1+v_{h}-\delta \frac{1+v_{h}}{1+\delta}>\max \left\{1-p_{x}+\delta\left(v_{h}-\frac{v_{h}}{1+d}\right), v_{h}-p_{y}+\delta\left(1-\frac{1}{1+\delta}\right)\right\}
$$

the $v_{h}$ type will offer $\delta\left(1+v_{h}\right) /(1+\delta)$ in equilibrium.

Of course, the $v_{h}$ type buyer only follows this strategy if it is better than following the $v_{l}$ type buyer's strategy. This requires that $1-p_{x}+\delta\left(v_{h}-v_{l} /(1+\delta)\right) \leq(1+$ $\left.v_{h}\right) /(1+\delta)$, or $p_{x} \geq \delta\left(1+v_{h}-v_{l}\right) /(1+\delta)-(1-\delta) v_{h}$. For any such offers on $X$ the seller will set $\omega_{t+1}=0$. The $p_{x}$ for which strict equality holds is the only value that survives refinement via Assumption 2. Further, for the seller to be willing to accept $p_{x}$ (rather than reject and counter with a joint offer of $\left.\left(1+v_{l}\right) /(1+\delta),\right) p_{x} \in[\delta /(1+\delta), 1]$. Finally, the signaling offer on $X$ is possible (i.e., $\left.p_{x} \leq 1\right)$ as long as $\delta\left(v_{h}-v_{l}\right)<1+\left(1-\delta^{2}\right) v_{h}$. This inequality is satisfied given $v_{h}-v_{l}<1$.

Proof of Lemma 3: Consider a joint offer $p=\left(p_{x}, p_{y}\right)$ and a deviation by the $v_{l}$ type using a sequence of partial offers. Under (A2) the uninformed will update beliefs to $\omega_{t+k}=0$ if he receives a partial offer $p_{x}$ and if the $v_{h}$ type strictly prefers the original strategy (joint offer of $p$ ) to the continuation path under the deviation, while the $v_{l}$ type prefers the deviation. If this partial offer is accepted, the highest possible continuation payoff to the informed if the partial offer is accepted arises if 
the uninformed makes the low valuation full information offer $v_{l} /(1+\delta)$. Thus, if there exists a $p_{x} \in[0,1]$ that is accepted by the seller and is such that

$$
\text { and } \begin{aligned}
1+v_{h}-p>1-p_{x}+\delta\left(v_{h}-\frac{v_{l}}{1+\delta}\right) \\
1+v_{l}-p<1-p_{x}+\delta\left(v_{l}-\frac{v_{l}}{1+\delta}\right)
\end{aligned}
$$

beliefs will be updated to $\omega_{t+1}=0$ by (A2) and stay at zero by (A1) for all continuation paths. (3) guarantees that the $v_{h}$ type finds the deviation to $p_{x}$ unprofitable while (4) guarantees that the $v_{l}$ type finds such a deviation profitable. For the seller to be willing to accept the offer $p_{x}$, it must be that acceptance yields higher utility than if the seller were to reject and counter with the price $\left(1+v_{l}\right) /(1+\delta)$ (he now is convinced of facing the low type, after all.) Such will be the case as long as $p_{x} \geq \delta /(1+\delta)$. The smallest $p$ such that the $v_{l}$ type finds deviation profitable is given by the $p$ for which (4) holds as an equality when $p_{x}=\delta /(1+\delta)$. This value of $p$ is given by $p=\delta\left(1+v_{l}\right) /(1+\delta)+(1-\delta) v_{l}$. The largest possible value of $p$ in any pooling equilibrium is $\left(1+v_{h}\right) /(1+\delta)$. Thus, for all $p$ such that $\left(\delta\left(1+v_{l}\right) /(1+\delta)+(1-\delta) v_{l} \leq p \leq\left(1+v_{h}\right) /(1+\delta)\right.$, the deviation to $p_{x}$ is successful for the $v_{l}$ type as long there exists a $p_{x} \leq 1$ that satisfies (3). Such is the case as long as $\delta\left(v_{h}-v_{l}\right)<1+(1-\delta) v_{l}$. This inequality is satisfied given $v_{h}-v_{l}<1$. qed

Proof of Lemma 4: This result follows immediately from Rubinstein's (1985) $\operatorname{Prop}^{n} 5$.

Proof of Lemma 5: The proof of this lemma consists of three parts. The first part shows that there is not an equilibrium in which the seller screens with a partial offer beginning with $X$. The second part shows that, for $\omega_{t} \geq \omega^{P}$ and $v_{l}$ not too small, there is not an equilibrium in which the seller screens with a joint offer while the buyer types pool. The final part shows that, if the seller makes a partial offer and the buyer types pool, the seller has an incentive to deviate to a joint offer. Combined, these three parts then prove the lemma.

i) no screening with an offer on $X$ only: 
Let $U_{s}^{s}$ be defined as the present value of the seller's utility under the proposed equilibrium should the buyer be of type $h$, neither issue is settled and it is the seller's turn to offer. $U_{s}^{b}$ is defined as the seller's utility when it is the buyer's turn to offer, neither issue has been settled, and the buyer is using a pooling strategy. These values are simply the present value of the price stream implied by the equilibrium path given the seller (buyer makes the offer).

For a proposed price path to be an equilibrium it must be that the $v_{h}$ type buyer is indifferent between accepting the seller's screening offer and rejecting and countering with the proposed pooling offer (if the $v_{h}$ type strictly preferred to accept the screening offer, then the $v_{l}$ type could reject and demand a price below the proposed equilibrium that the seller would accept). The $v_{l}$ type buyer strictly prefers to reject the screening offer. If the seller screens with a partial offer beginning with $X$, this fact implies that, $1+\delta v_{h}-U_{s}^{s}=\delta+\delta v_{h}-\delta U_{s}^{b}$ and that $1+\delta v_{l}-U_{s}^{s}<\delta+\delta v_{l}-\delta U_{s}^{b}$. These conditions cannot both hold simultaneously, ruling out this strategy as a screening strategy.

ii) no screening with joint offers:

Lemmas 1 and 3 establish that, for $\omega_{t} \geq \omega^{P}$, the only possible equilibrium with seller screening using a joint offer must have the buyer making a pooling offer beginning with $X$. As above, any equilibrium of this sort must satisfy the condition $1+v_{h}-U_{s}^{s}=\delta\left[1+\delta v_{h}-U_{s}^{b}\right]$; equivalently, $U_{s}^{s}=\delta U_{s}^{b}+\left(1+(1+\delta) v_{h}\right)(1-\delta)$. The lowest discounted price stream that the buyer could extract in any such equilibrium must satisfy the condition $U_{s}^{b}=\delta\left[\omega_{t} U_{s}^{s}+\delta\left(1-\omega_{t}\right) U_{s}^{b}\right]$. This condition implies that $U_{s}^{b}=\left(\delta \omega_{t} U_{s}^{s}\right) /\left(1-\delta^{2}\left(1-\omega_{t}\right)\right)$. Substituting for $U_{s}^{b}$ in the above yields $U_{s}^{s}=\left[1-\delta^{2}\left(1-\omega_{t}\right)\right]\left[1+v_{h}(1+\delta)\right] /(1+\delta)$. This offer yields utility for the $v_{h}$ type buyer of $U_{b}^{h}=\delta+\delta^{2}\left(1-\omega_{t}\right) v_{h}-\left(\delta^{2} \omega_{t}\right) /(1+\delta)$. For these strategies to comprise an equilibrium, $U_{b}^{h} \geq \delta\left(1+v_{h}\right) /(1+\delta)$. Such will be the case only if $1-\omega_{t} \geq v_{h} /\left(\delta\left[1+v_{h}(1+\delta)\right]\right)$. This value will be less than $\omega^{P}$ if

$$
1-\frac{1+v_{l}}{1+v_{h}} \leq \frac{\left(1-\delta^{2}\right) v_{h}}{\delta\left(1+v_{h}\right)}+\frac{v_{h}}{\delta\left(1+v_{h}(1+\delta)\right)} .
$$

Since the RHS of this inequality is decreasing in $\delta$, this condition is guaranteed to be 
satisfied if it holds for $\delta=1$. Such will be the case if $v_{h}\left(v_{h}-2 v_{l}\right) \leq v_{l}$. This condition is satisfied given $v_{l} \geq \underline{v}$.

iii) Seller has incentive to deviate from a partial offer

From the above and following from Lemma 4, the seller either screens with a partial offer beginning with $Y$ or pools with a partial offer beginning with $X$. In both cases, the seller has an incentive to deviate to a joint offer. Consider, first, the screening case. The seller's offer must be such that the $v_{h}$ type is indifferent between accepting and rejecting while the $v_{l}$ type strictly prefers to reject. This condition will be $v_{h}+\delta-U_{s}^{s}=\delta+\delta v_{h}-\delta U_{s}^{b}, v_{l}+\delta-U_{s}^{s}<\delta+\delta v_{l}-\delta U_{s}^{b}$ if the buyer makes a joint offer and $v_{h}+\delta-U_{s}^{s}=\delta+\delta^{2} v_{h}-\delta U_{s}^{b}, v_{l}+\delta-U_{s}^{s}<\delta+\delta^{2} v_{l}-\delta U_{s}^{b}$ if the buyer makes a partial offer.

Consider the case in which the buyer makes a joint offer and imagine a deviation by the seller to a joint offer, $\hat{P}$, that yields the $v_{h}$ type the same utility as the partial screening offer. This offer is defined by $v_{h}+\delta-U_{s}^{s}=v_{h}+1-\hat{P}$; or $\hat{P}=U_{s}^{s}+1-\delta$. Because the $v_{h}$ type continues to be indifferent, the $v_{l}$ type must strictly prefer to reject this offer. The seller strictly prefers this offer to the partial screening offer. As a consequence, the seller can offer $\widehat{P}+\varepsilon, \varepsilon$ positive, such that the $v_{h}$ type buyer prefers to accept rather than reject and offer $U_{s}^{b}$, the $v_{l}$ type buyer prefers to reject and the seller is better off. This deviation is possible for all $U_{s}^{b}$; in particular, it is possible for the $U_{s}^{b}$ that yields the buyer the maximum possible payoff among all such screening equilibria.

Analogous arguments hold for the case of screening when the buyer makes a partial offer as well as for the case of the seller pooling on a partial offer beginning with $X$. Thus, if any of these outcomes are to be supported as equilibria, it must be that the deviation by the seller to $\widehat{P}$ is met by a switch to some other equilibrium path involving patterns of offers different from those in the proposed equilibrium (for instance, if the seller is deviating from a partial offer screening path, the deviation must be met by a switch to a partial offer pooling path). 
The proof of the lemma can now be completed. Consider a proposed equilibrium in which the seller screens with a partial offer beginning with $Y$. From the above, the seller can deviate to a joint offer, $\widehat{P}$, which, if accepted by the $v_{h}$ type yields higher utility for the seller than the proposed path. For the deviation not to be successful, then, the $v_{h}$ type must reject the offer. A rejection can only be in the $v_{h}$ type's interest if the utility received from rejection in the continuation equilibrium is greater than $1+v_{h}-\hat{P}$. Consider, then, possible continuations after a rejection by the buyer. A separating outcome yields the $v_{h}$ type the lowest utility among all possible equilibria and so he will not reject $\widehat{P}$ if rejection is followed by a separating outcome. Given a rejection must leave $\omega_{t}$ unchanged, the above results imply that the only other possibilities have the seller making a partial offer also. Each of these also provides the seller with an incentive to deviate and so can only support the desired outcome if the sequence of prices, $\hat{P}$ is strictly declining. This sequence violates the fact that $\widehat{P} \geq\left(1+v_{l}\right) /(1+\delta)$ and so no such equilibrium can be supported. qed Proof of Result 2: Lemma 2 has provided the necessary separating strategies. These will yield the seller an expected payoff of

$$
\begin{aligned}
& \omega_{t}\left[\frac{1+v_{h}}{1+\delta}\right]+\delta\left(1-\omega_{t}\right)\left[p_{x}+\delta \frac{v_{l}}{1+\delta}\right]= \\
& \omega_{t}\left[\frac{1+v_{h}}{1+\delta}\right]+\delta\left(1-\omega_{t}\right)\left[1-\frac{1+v_{h}}{1+\delta}+\delta\left(v_{h}-\frac{v_{l}}{1+\delta}\right)+\delta \frac{v_{l}}{1+\delta}\right]= \\
& \omega_{t}\left[\frac{1+v_{h}}{1+\delta}\right]+\delta\left(1-\omega_{t}\right)\left[1+\delta v_{h}-\frac{1+v_{h}}{1+\delta}\right]= \\
& \delta\left[\frac{\delta\left(1+v_{h}\right)}{1+\delta}-(1-\delta) v_{h}\right]+\omega_{t}\left[(1-\delta)\left(1+v_{h}(1+\delta)\right)\right] .
\end{aligned}
$$

Here we used the $p_{x}$ derived in Lemma 2. We next consider possible deviations from these strategies.

First, the seller could deviate to an offer that both buyers accept. Lemma 4 implies that offers on $Y$ alone or joint offers on $X$ and $Y$ together yield the same payoff as simply conceding (asking for $\left(1+v_{l}\right) /(1+\delta)$ ). Such a deviation is profitable only if

$$
\frac{1+v_{l}}{1+\delta} \geq \delta\left[\frac{\delta\left(1+v_{h}\right)}{1+\delta}-(1-\delta) v_{h}\right]+\omega_{t}\left[(1-\delta)\left(1+v_{h}(1+\delta)\right)\right]
$$




$$
\omega_{t} \leq 1-\frac{v_{h}-v_{l}}{\left(1-\delta^{2}\right)\left(1+v_{h}(1+\delta)\right)}=\omega^{S 1}
$$

Note that $\omega^{S 1}<\omega^{*}$ by the following sequence of implications:

$$
\begin{aligned}
\frac{1+v_{l}}{1+v_{h}} & \geq 1-\frac{v_{h}-v_{l}}{\left(1-\delta^{2}\right)\left(1+v_{h}(1+\delta)\right)} \\
\frac{v_{h}-v_{l}}{\left(1-\delta^{2}\right)\left(1+v_{h}(1+\delta)\right)} & \geq \frac{v_{h}-v_{l}}{1+v_{h}} \\
1+v_{h} & \geq\left(1-\delta^{2}\right)\left(1+v_{h}(1+\delta)\right) \\
0 & \geq v_{h}\left(1-\delta^{2}\right)-\delta\left(1+v_{h}\right) \\
\left(1-\delta^{2}\right)+\delta\left(1+v_{h}\right) & \geq\left(1-\delta^{2}\right)\left(1+v_{h}\right),
\end{aligned}
$$

but by $(\mathrm{A} 4)\left(1-\delta^{2}\right)\left(1+v_{h}\right)<\delta\left(v_{h}-v_{l}\right)$ and

$$
\begin{aligned}
\left(1-\delta^{2}\right)+\delta\left(1+v_{h}\right) & \geq \delta\left(v_{h}-v_{l}\right) \\
\text { since } 1-\delta^{2}+\delta & \geq-\delta v_{l} .
\end{aligned}
$$

Second, the seller could deviate to just an offer on $X$ which both types accept, which is followed by the screening equilibrium on $Y$ at the original beliefs. For the seller such a deviation is profitable if

$$
\hat{p}_{x}+\delta \frac{\delta \omega_{t} v_{h}}{1+\delta} \geq \delta\left[\frac{\delta\left(1+v_{h}\right)}{1+\delta}-(1-\delta) v_{h}\right]+\omega_{t}\left[(1-\delta)\left(1+v_{h}(1+\delta)\right)\right]
$$

Both buyer types would accept such a $\hat{p}_{x}$ if

$$
\begin{aligned}
1-\hat{p}_{x}+\delta\left(v_{h}-\frac{\delta \omega_{t} v_{h}}{1+\delta}\right) & \geq \delta \frac{1+v_{h}}{1+\delta} \\
\text { and } 1-\hat{p}_{x}+\delta\left(v_{l}-\frac{\delta \omega_{t} v_{h}}{1+\delta}\right) & \geq \delta \frac{1+v_{h}}{1+\delta}-\delta^{2}\left(v_{h}-v_{l}\right) \text {. }
\end{aligned}
$$

Here we have already simplified the $v_{l}$ type's payoff from the signaling strategies. It is easy to verify that $(7)$ is the binding constraint on $\hat{p}_{x}$, and simplification yields

$$
\hat{p}_{x} \leq 1+\delta v_{l}-\frac{\delta^{2} \omega_{t} v_{h}}{1+\delta}-\delta \frac{1+v_{h}}{1+\delta}+\delta^{2}\left(v_{h}-v_{l}\right)
$$

A $\hat{p}_{x}$ that satisfies both (5) and (7) fails to exist if

$$
\omega_{t} \geq \frac{1+v_{l}}{1+v_{h}(1+\delta)}=\omega^{S 2}
$$


Note that $\omega^{S 2}<\omega^{*}$.

Third, the seller could deviate to screen on $Y$ first, but it is easy to verify that screening on both issues simultaneously (as in the proposed equilibrium strategies) has a higher payoff.

As far as the buyers are concerned, both types of buyer could deviate to a joint offer. By (A3) such a deviation is followed by setting $\omega_{t+1}=1$, and thus would be rejected unless the price is equal to the high valuation player's full information share - which he already obtains in equilibrium, and we know that the low valuation type receives more under the separating strategies.

Next, consider a deviation by both types to a pooling offer on $X$. Given that the proposed equilibrium strategy for the $v_{l}$ type yields the lowest possible price for $Y$ of any equilibrium, this type is willing to undertake the deviation only if $p_{x}<$ $\delta\left(1+\left(v_{h}-v_{l}\right)\right) /(1+\delta)-(1-\delta) v_{h}$. Further, total payment (appropriately discounted) must be strictly less under the deviation than under the proposed equilibrium. The seller will only accept this deviating offer if the payoff from doing so is greater than that from rejecting and countering with the proposed separating offer given priors $\omega_{t+1}=\omega_{t}$ (Assumption 3). The value of total payments to the seller from accepting the equilibrium offer, $p_{x}$, is

$$
\delta \frac{1+\left(v_{h}-v_{l}\right)}{1+\delta}-(1-\delta) v_{h}+\frac{\delta v_{l}}{1+\delta} .
$$

The expected value of total payments, discounted one period, under the seller's equilibrium separating offer with prior $\omega_{t}$ is

$$
\delta\left(\delta\left[\frac{\delta\left(1+v_{h}\right)}{1+\delta}-(1-\delta) v_{h}\right]+\omega_{t}\left[(1-\delta)\left(1+v_{h}(1+\delta)\right)\right]\right) .
$$

Simple manipulation shows that $(8)<(9)$ if

$$
\omega_{t}>1-\frac{v_{h}}{\delta\left[1+v_{h}(1+\delta)\right]}
$$

The RHS of this inequality will be less than $\omega^{*}$ as long as $v_{h}\left(v_{h}-2 v_{l}\right)<v_{l}$. This condition is satisfied for $v_{l} \geq \underline{v}$. Thus, the seller will not accept the proposed deviating offer. 
Finally, the buyers could deviate to a pooling offer on $Y$ first. Since the $v_{l}$ type prefers the order $X$ then $Y$ over $Y$ then $X$ at constant total payment, such a deviation is profitable for this type only if total payment falls. It has already been shown, however, that the seller rejects an offered total payment less than that associated with the $v_{l}$ type's equilibrium strategy and so any such deviation is also rejected. This then concludes the proof that the above strategies constitute an equilibrium.

It remains to verify that no other equilibria exist. Lemma 2 states that any separating/signaling equilibrium must employ the above strategies, so any other equilibria would have to have the buyers pooling on their offers. By Lemma 1 no equilibria exist in which they pool on just a $Y$ offer. Lemma 3 shows that if they pool on a joint offer in equilibrium then $\omega_{t}$ must be less than $\omega^{P}$. The only remaining possibility is pooling by the buyers on an offer on $X$ only, but in the second part of the proof of Lemma 5 it was shown that such an equilibrium cannot exist.

qed

Partial Proof of Result 3: We will first derive the $\omega^{P 2}$ cutoff for this case. Then we will demonstrate that the strategies constitute an equilibrium. Finally, we will argue the case for uniqueness. First note that $p_{2}=(1-\delta)\left(1+v_{l}-p_{1}\right)$, as per the discussion preceding the result. It follows that the total price to be paid, $p_{1}+p_{2}=(1-\delta)\left(1+v_{l}\right)+\delta p_{1}$.

Consider the arguments of Lemma 3 applied to this case. From a joint offer $P$ the $v_{l}$ type can deviate to a partial offer if

$$
\begin{aligned}
1+v_{h}-P & \geq \delta\left(1+v_{h}-\delta p_{1}-(1-\delta)\left(1+v_{l}\right)\right) \\
1+v_{l}-P & \leq \delta\left(1+v_{l}-\delta p_{1}-(1-\delta)\left(1+v_{l}\right)\right)=\delta^{2}\left(1+v_{l}\right)-\delta^{2} p_{1}
\end{aligned}
$$

Recall that $p_{1}>\delta\left(1+v_{l}\right) /(1+\delta)$ is required in order to have the necessary corner solution in the second bargain. The lowest $P$ for which a deviation is available and profitable is therefore given when (11) holds as an equality with $p_{1}=\delta\left(1+v_{l}\right) /(1+\delta)$ :

$$
P=\left(1+v_{l}\right)\left(1-\delta^{2}\right)+\delta^{3} \frac{1+v_{l}}{1+\delta}=\frac{1+v_{l}}{1+\delta}\left(1+\delta-\delta^{2}\right)
$$


From Result 1 we know the screening joint price offer of $\delta \omega_{t}\left(1+v_{h}\right) /(1+\delta)$. Thus we know that for $\omega_{t}$ such that

$$
\begin{aligned}
\frac{\delta \omega_{t}\left(1+v_{h}\right)}{1+\delta} & \geq \frac{1+v_{l}}{1+\delta}\left(1+\delta-\delta^{2}\right) \Longrightarrow \\
\omega_{t} \geq \omega^{P 2} & =\frac{1+v_{l}}{1+v_{h}} \frac{1+\delta-\delta^{2}}{\delta}=\omega^{*} \frac{1+\delta-\delta^{2}}{\delta}
\end{aligned}
$$

a deviation exists which destroys pooling on joint offers. (A4) implies that $\omega^{P 2}<1$, while $\delta<1$ implies that $\omega^{*}<\omega^{P 2}$.

The payoffs to the players from following their equilibrium offer strategies as laid out in the proposition are

$$
\begin{aligned}
v_{h} \text { type } & : \frac{1+v_{h}}{1+\delta} \\
v_{l} \text { type } & : \frac{1+v_{h}}{1+\delta}-\delta\left(v_{h}-v_{l}\right) \\
\text { Seller } & : \frac{\delta\left(1+v_{h}\right)(\delta(1+\delta)-1)}{1+\delta}+\omega_{t}\left(1-\delta^{2}\right)\left(1+v_{h}\right) .
\end{aligned}
$$

Here the seller's offer strategy if no price has yet been agreed upon and it is his turn is to offer $\left(1+v_{h}\right) /(1+\delta)$, which only the $v_{h}$ type accepts. Note that the high valuation player is indifferent between his and the low valuation player's equilibrium offer strategy if:

$$
\frac{1+v_{h}}{1+\delta}=\delta\left(1+v_{h}-p_{1}-p_{2}\right)=\delta\left(1+v_{h}-\delta p_{1}-\left(1+v_{l}\right)(1-\delta)\right) .
$$

Solving for $p_{1}$ we obtain the expression in the result,

$$
p_{1}=\left(1+v_{l}\right)+\frac{v_{h}-v_{l}}{\delta}-\frac{1+v_{h}}{\delta^{2}(1+\delta)}
$$

The low valuation player, on the other hand, strictly prefers his offer strategy to that of the high valuation player if

$$
\begin{gathered}
1+v_{l}-\delta \frac{1+v_{h}}{1+\delta}=\frac{1+v_{l}}{1+\delta}-\frac{\delta\left(v_{h}-v_{l}\right)}{1+\delta}<\frac{1+v_{h}}{1+\delta}-\delta\left(v_{h}-v_{l}\right), \\
\Longrightarrow \frac{\delta^{2}\left(v_{h}-v_{l}\right)}{1+\delta}<\frac{v_{h}-v_{l}}{1+\delta}
\end{gathered}
$$


which it clearly is. This also implies that the updating of beliefs to $\omega_{1}=0$ after the partial offer $p_{1}$ is consistent with (A2), and thus that the offer $p_{2}$ as computed before is the appropriate continuation.

As in Result 2, no joint deviation by both informed players is possible. If they were to deviate to a joint offer $p_{x}+p_{y}$ preferred to both, the seller is justified in setting $\omega_{t+1}=1$. Hence any joint price below $\delta\left(1+v_{h}\right) /(1+\delta)$ is rejected. The buyers could, of course, deviate to a partial offer $\hat{p}_{1}$. If both buyers prefer this deviation (if accepted) to their equilibrium strategies the seller can at most keep his beliefs constant. It is straight forward but tedious to verify that the seller will reject any such deviations in favor of continuing to separate the buyers as long as $\omega_{t}$ is large enough and that the critical $\omega_{t}$ value lies below $\omega^{*}$ which is less than $\omega^{P 2}$.

Next, consider a deviation by both buyer types to a pooling offer on a single good that is below the proposed equilibrium price, $p_{1}$. As in the proof of Result 2 , this offer is rejected by the seller as long as the total payment under the proposed equilibrium offer for the $v_{l}$ type is less than the expected payment, appropriately discounted and given priors $\omega_{t}$, under the sellers proposed equilibrium strategy. That is, the deviating offer is rejected if

$$
\begin{gathered}
1+v_{l}+\frac{v_{h}-v_{l}}{\delta}-\frac{1+v_{h}}{\delta^{2}(1+\delta)}+(1-\delta)\left[\frac{1+v_{h}}{\delta^{2}(1+\delta)}-\frac{v_{h}-v_{l}}{\delta}\right]< \\
\frac{\delta\left(1+v_{h}\right)(\delta(1+\delta)-1)}{1+\delta}+\omega_{t}\left(1-\delta^{2}\right)\left(1+v_{h}\right) .
\end{gathered}
$$

Some manipulation yields that this inequality is satisfied if

$$
\left(\delta+\delta^{2}-1\right) \frac{1-\delta^{2}}{\delta}<\omega_{t}\left(1-\delta\left(\delta+\delta^{2}-1\right)\right)
$$

As the RHS of this inequality is increasing in $\omega_{t}$, it will be satisfied for all relevant beliefs if it is satisfied at $\omega_{t}=\omega^{*}$. Substitution for this value of $\omega_{t}$ yields the inequality

$$
\frac{1+v_{h}}{\delta(1+\delta)}>v_{h}-v_{l}
$$

which is guaranteed by the assumption that $v_{h}-v_{l}<1$. Therefore, the seller rejects the deviating offer. 
Finally, seller deviations. Observe that if the seller screens the buyers on only one issue this is equivalent to screening them on both due to the joint implementation. Screening with joint offers also generates the largest payoff of all screening equilibria for the seller, so he would not deviate. On the other hand, if the seller were to deviate to a sequence of offers which both buyers accept (no screening), then the highest payoff he can obtain from such a strategy is $\left(1+v_{l}\right) /(1+\delta)$ (by implication from Rubinstein's Proposition 5 (1985).) Thus, the seller will only deviate to such a sequence if

$$
\frac{1+v_{l}}{1+\delta}>\frac{\delta\left(1+v_{h}\right)(\delta(1+\delta)-1)}{1+\delta}+\omega_{t}\left(1-\delta^{2}\right)\left(1+v_{h}\right)
$$

This requires

$$
\omega_{t}<\frac{\omega^{*}+\left(\delta-\delta^{2}(1+\delta)\right)}{(1+\delta)\left(1-\delta^{2}\right)}=\omega^{S}
$$

Manipulation verifies that $\omega^{S}<\omega^{*}<\omega^{P 2}$ under (A4).

Finally to uniqueness. It is easy to verify that any separating strategies must be of the type in the proposition, since the $v_{h}$ type must pay his full information price by the standard arguments. Therefore we only need to check for any pooling equilibria (that is, equilibria in which both types make the same offer which is accepted.) We already argued above that pooling on a joint offer in conjunction with screening by the seller will break down above $\omega^{P 2}$. If the buyers where to pool on a partial offer that is accepted, then this could be followed by screening on the remaining issue (note that with one issue remaining there do not exist signaling equilibria in the continuation paths.) But these strategies would lead to the same total price for the seller, only delayed by one (or two) period(s). The $v_{l}$ type would again have a signaling deviation and thus no equilibria of this type exist either, in this region of initial beliefs. qed 


\section{References}

Admati, A. and M. Perry (1987): "Strategic Delay in Bargaining," Review of Economic Studies, vol. LIV, 345-364.

Bac, M. and H. Raff (1996): "Issue-by-Issue Negotiations: The Role of Information and Time Preferences," Games and Economic Behavior, vol. 13, p.125.

Beckmann, N. (1977): Negotiations: Principles and Techniques, Lexington Books, D.C. Heath and Co., Lexington, Massachusetts.

Busch, L-A. and I. Horstmann (1999a): "Signaling via an agenda in multi-issue bargaining with incomplete information," Economic Theory, vol. 13, 561-576.

Busch, L-A. and I. Horstmann (1999b): "Endogenous Incomplete Contracts: A Bargaining Approach," Canadian Journal of Economics, forthcoming.

Busch, L-A. and I. Horstmann (1997): “A Comment on Issue-by-Issue Negotiations," Games and Economic Behavior, vol. 19, 144-148.

Busch, L-A. and Q. Wen (1995): “Perfect Equilibria in a Negotiation Model," Econometrica, vol. $63,545-565$.

Cho, I. (1987): “A Refinement of Sequential Equilibrium," Econometrica, vol. 55, 1367-1389.

Cho, I. and D. Kreps (1987): "Signaling Games and Stable Equilibria," Quarterly Journal of Economics, vol. CII, 179-221.

Churchman, D. (1995): Negotiation Process, Tactics, Theory, 2nd edition, University Press of America, Lanham, New York.

Edwards, H. and J. White, (1977): The Lawyer as Negotiator: Problems, Readings and Materials, West Publishing Co. 
Fernandez, R. and J. Glazer (1991): "Striking for a Bargain Between Two Completely Informed Agents", American Economic Review, vol. 81, 240-252.

Fershtman, C. (1990): "The Importance of the Agenda in Bargaining," Games and Economic Behavior, vol. 2, 224-238.

Fudenberg, D., D. Levine, and J. Tirole (1985): “Infinite-Horizon Models of Bargaining with One-Sided Incomplete Information", in A. Roth ed., Game-Theoretic Models of Bargaining, Cambridge University Press, pp.73-98.

Game-Theoretic Models of Bargaining, A. Roth ed. (1985): Cambrige: Cambridge University Press.

Grossman, S. and M. Perry (1986): "Sequential Bargaining Under Asymmetric Information", Journal of Economic Theory, vol. 39, pp. 120-54.

Haller, H. and S. Holden (1990): "A Letter to the Editor on Wage Bargaining", Journal of Economic Theory, vol. 52, 232-236.

Herrero, Maria J. (1989): “Single-Package versus Issue-by-Issue Bargaining,” mimeo.

Inderst, R. (1998): “Multi-issue bargaining with endogenous agenda," mimeo.

Kalai, E. (1977): "Proportional Solutions to Bargaining Situations: Interpersonal Utility Comparisons," Econometrica, vol. 45, 1623-1630.

Jun, B (1989): “Non-cooperative Bargaining and Union Formation," Review of Economic Studies, vol. 56(1), 59-76.

Lang, K., and R.W. Rosenthal (1998): "Multi-issue Bargaining with Perfect Information," mimeo April 1998.

Lewis, David V. (1981): Power Negotiating Tactics and Techniques, Prentice-Hall Inc., Englewood Cliffs, New Jersey. 
Myerson, R. and M. Satterthwaite (1983): “Efficient Mechanisms for Bilateral Trading", Journal of Economic Theory, vol. 29, pp. 265-81.

Perry, M. (1986): “An Example of Price Formation in Bilateral Situations: A Bargaining Model with Incomplete Information," Econometrica, vol. 54, 313-321.

Ponsati, C. and J. Watson (1997): “Multiple Issue Bargaining and Axiomatic Solutions," International Journal of Game Theory, vol.26, 501-24.

Ramundo, Bernard A. (1992): Effective Negotiation: A Guide to Dialogue Management and Control, Quorum Books, New York.

Rubinstein, A. (1982): "Perfect Equilibrium in a Bargaining Model," Econometrica, vol. $50,97-110$.

Rubinstein, A. (1985): “A Bargaining Model with Incomplete Information about Time Preferences," Econometrica, vol. 53, 1151-1171.

Rubinstein, A. (1987): "A Sequential Strategic Theory of Bargaining", in T. Bewley ed., Advances in Economic Theory: Fifth World Congress, Cambridge University Press, pp.197-224.

Weinberger, C.J. (1997): "Selective Acceptance and Inefficiency in a two-issue complete information bargaining game," mimeo.

Wilson, R. (1987): “Game-Theoretic Analyses of Trading Processes," in Advances in Economic Theory, ed. by T. Bewley. Cambridge: Cambridge University Press. 